\section{BMJ Open} Ophthalmology

\title{
Clinical safety of a minor eye conditions scheme in England delivered by community optometrists
}

\author{
Evgenia Konstantakopoulou, ${ }^{1,2,3}$ Robert A Harper, ${ }^{4}$ David F Edgar, ${ }^{1}$ \\ Genevieve Larkin, ${ }^{5}$ Sarah Janikoun, ${ }^{6}$ John G Lawrenson ${ }^{1}$
}

To cite: Konstantakopoulou E, Harper RA, Edgar DF, et al. Clinical safety of a minor eye conditions scheme in England delivered by community optometrists. BMJ Open Ophthalmology 2018:3:e000125. doi:10.1136/ bmjophth-2017-000125

- Additional material is published online only. To view please visit the journal online (http://dx.doi.org/10.1136/ bmjophth-2017-000125).

Received 20 September 2017 Revised 9 January 2018 Accepted 29 January 2018

Check for updates

${ }^{1}$ Division of Optometry and Visual Science, Centre for Applied Vision Research, City University of London, London, UK

${ }^{2}$ NIHR Biomedical Research Centre, Moorfields Eye Hospital NHS Foundation Trust, London, UK

${ }^{3}$ University College London, Institute of Ophthalmology, London, UK

${ }^{4}$ Manchester Academic Health Science Centre, Manchester Royal Eye Hospital, Manchester University Hospitals NHS Foundation Trust, Manchester, UK

${ }^{5}$ King's College Hospital NHS Foundation Trust, London, UK ${ }^{6}$ Guy's and St Thomas' NHS Foundation Trust, London, UK

Correspondence to Dr Evgenia Konstantakopoulou; evgenia.konstantakopoulou@ moorfields.nhs.uk

\section{ABSTRACT}

Objective The aim of this study was to monitor the activity and evaluate the clinical safety of a minor eye conditions scheme (MECS) conducted by accredited community optometrists in Lambeth and Lewisham, London.

Methods and analysis Optometrists underwent an accredited training programme, including attendance at hospital eye services (HES) clinics. Patients who satisfied certain inclusion criteria were referred to accredited MECS optometrists by their general practitioners (GPs) or could self-refer. Data were extracted from clinical records. A sample of MECS clinical records was graded to assess the quality of the MECS optometrists' clinical management decisions. Referrals to the HES were assessed by the collaborating ophthalmologists and feedback was provided. Results A total of 2123 patients (mean age 47 years) were seen over 12 months. Two-thirds of the patients $(67.3 \%)$ were referred by their GP. The most common reasons for patients needing a MECS assessment were 'red eye' (36.7\% of patients), 'painful white eye' (11.1\%), 'flashes and floaters' (10.2\%); $8.7 \%$ of patients had a follow-up appointment. Of the patients seen, $75.1 \%$ were retained in the community, $5.7 \%$ were referred to their GP and $18.9 \%$ were referred to the HES. Of the HES referrals, $49.1 \%$ were routine, $22.6 \%$ urgent and $28.3 \%$ emergency. Of the records reviewed, $94.5 \%$ were rated as appropriately managed; $89.2 \%$ of the HES referrals were considered appropriate.

Conclusion The findings of this study indicate that optometrists are in a good position to work very safely within the remits of the scheme and to assess risk.

\section{INTRODUCTION}

Over the last decade, there has been a $40 \%$ increase in eye-related hospital visits across the UK and ophthalmology currently accounts for approximately $10 \%$ of all National Health Service (NHS) outpatient attendances. ${ }^{1-3}$ In addition to the burden associated with chronic eye disease, there is an escalating problem delivering emergency eye care services. For example, the number of patients attending the two largest emergency eye units in London is increasing by $7.9 \%$ and $9.6 \%$ per year. ${ }^{4}$ There is growing recognition that rising demands on eye care

\section{Key messages}

What is already known about this subject?

- Rising demands on eye care services may result in delays and poorer visual outcomes for those waiting for treatment. Despite the widespread adoption of optometric Enhanced Service Schemes (ESS) across the UK, there is a lack of information on clinical safety, patient satisfaction and cost effectiveness.

\section{What are the new findings?}

We report clinical safety data, demonstrating that community optometrists can assess and manage patients safely, within the remits of optometric ESS.

How might these results change the focus of research or clinical practice?

Ophthalmologist and general practitioner collaboration with the optometrist is desirable for the development of safe and efficient optometric ESS that will operate under a robust clinical governance framework.

services may result in delays and poorer visual outcomes for those waiting for treatment or disease monitoring. ${ }^{56}$ There is an urgent need to manage the flow of patients between primary and secondary care and evaluate emerging technology to facilitate clinical decision-making to ensure that patients are seen by the most appropriate healthcare professional, in the most appropriate setting, and in a timely manner to minimise the likelihood of visual loss.

In the UK, ophthalmic care is primarily provided by community optometrists, general practitioners (GPs), community pharmacists and the Hospital Eye Service (HES). Optometrists provide primary ophthalmic care and sight tests. GPs also provide primary ophthalmic care as patients often present to their GP with an eye-related problem which has the potential to be managed by their optometrist. The HES provides secondary ophthalmic care either via outpatient clinics or at an accident and emergency (A\&E) level; 
although the latter has been designed for secondary care provision, it is increasingly used for primary care. Up to $70 \%$ of ophthalmic A\&E cases could be managed in the community (eg, a community optometrist) ${ }^{7-11}$; additionally, many of the patients attending ophthalmic A\&E departments are discharged without the need for a subsequent outpatient appointment. ${ }^{12}$ Optometrists have been considered responsible for most routine ophthalmic referrals to the $\mathrm{HES}^{1314}$; it was, however, recently shown that the majority of walk-ins to a London specialised ophthalmic A\&E department self-refer, very often for 'convenience'. ${ }^{47}$

In an effort to ease overstretched HES resources, a number of enhanced service schemes (ESSs) have been introduced in the UK. These schemes aim to refine HES referrals via either confirming the necessity of the referral or managing the patient in a community setting. A number of minor/anterior eye condition schemes have been launched in the UK, which aim to reduce A\&E workload, assist GPs and increase patients' accessibility to specialist professional equipment and skills. ${ }^{15}$ Despite their widespread adoption across the UK, there is a dearth of formal evaluation of ESSs in terms of clinical safety, patient satisfaction and cost effectiveness. Subsequently, the safety and generalisability of the schemes remains unknown. The aim of this study was to monitor the activity and evaluate the clinical safety of a minor eye conditions scheme (MECS) in Lambeth and Lewisham, London. Patient satisfaction and cost effectiveness of the scheme have been reported elsewhere. ${ }^{16-18}$

\section{METHODS}

The MECS

The scheme has been previously described elsewhere. ${ }^{19}$ In brief, the scheme was launched in April 2013 using 10 optometrists based in 13 community optometric practices. Participating optometrists were appropriately trained and accredited and a further requirement was that they should be successful in an assessment of key clinical skills via a practical station examination. Optometrists were not required to obtain a specialist prescribing qualification, but were permitted to supply certain medications according to the Medicines Act exemptions legislation. ${ }^{20}$ Additionally, optometrists were required to observe in HES clinics and they maintained contact, on a scheduled basis, with two consultant ophthalmologists at either King's College Hospital or Guy's and St Thomas's Hospital; both ophthalmologists were also seconded to MECS. Each ophthalmologist had one allocated MECS clinical session per week, with a remit to review clinical records of patients referred to the HES via the scheme. In addition, the ophthalmologists delivered ongoing mentoring and continuing education to the optometrists involved in the scheme.

Those patients who attended their GP practice with symptoms of red eye, loss of vision, trauma, headaches, painful white eye, and flashes and floaters were referred to the scheme's optometrists. Alternatively, patients could self-refer to any optometrist accredited to MECS. After the MECS assessment, which took place within 48 hours, patients were either managed within the optometric practice or referred to the HES; a further option for patients was a referral to their GP for systemic investigations.

\section{Scheme activity and data collection}

For the current study, a period of 12 calendar months from September 2013 to August 2014 was chosen and data were collected from all patients examined in MECS during that period who gave informed consent for collection of their fully anonymised clinical data. Each patient's age, first part of postcode, ethnicity, GP details, presenting complaint, vision and/or visual acuity, diagnosis, management and, where applicable, the HES to which that referral was made, the urgency of referral and the HES diagnosis were extracted from clinical records and entered onto a secure database.

Referrals to the collaborating HES (Guy's and St Thomas's Hospital and King's College Hospital) were assessed by participating ophthalmologists; the research team had access to the diagnosis made in the HES for referred patients, and these diagnoses were compared with those made by the MECS optometrists. The HES ophthalmologists provided feedback on how appropriate each referral was and whether each referral was made with appropriate urgency. The International Classification of Diseases codes by $\mathrm{WHO}^{21}$ was employed to record each patient's diagnosis, whether this was made in the community, in the HES or in both locations.

\section{Clinical safety}

A random sample of 44 clinical records of patients examined in MECS optometric practices were initially assessed by all four members of the research team, and good agreement on the practitioners' patient management of each case was established using multiple kappa values. A randomly selected sample of 220 MECS clinical records (stratified by practitioner), comprising approximately $10 \%$ of all records of patients seen through MECS during the study period, was then reviewed and independently graded by four members of the research team. Since agreement among the members of the research team had been established, the records were randomly assigned to four equal-sized groups, and each group of records was reviewed by one grader. Records were made available via http://www.dropbox.com, and a recording sheet for each grader was made available on http://www. surveymonkey.com. The College of Optometrists Clinical Management Guidelines ${ }^{22}$ and the PEARS guidelines on flashes and floaters, produced by Optometry Wales and the Wales Optometry Postgraduate Education Centre (WOPEC), ${ }^{23}$ were used by the graders as reference material, which allowed them to assess the quality of the MECS optometrists' clinical management for each patient record reviewed. The above guidelines had been made available to the participating community optometrists during their training. 
The researchers reviewed each record independently and graded MECS optometrists' clinical care for each patient as either 'appropriate' or 'inappropriate'. A grading of appropriate care was given when the optometrist's assessment and management of the patient was completely or substantially in accordance with the reference guidelines or when management, although deficient in some aspects of care proposed in the guidelines, was regarded as carrying no risk to patient safety. Patient care was graded as inappropriate where the optometrist had assessed and/or managed the patient in a way that was inappropriate based on the reference guidelines and/or was regarded as unsafe. In cases where patient care was deemed 'inappropriate', the reviewing optometrist gave the rationale for their decision by choosing one or more of the following options: prescription error, inappropriate non-referral, inappropriate referral, inappropriate referral urgency, inappropriate discharge and/or other. All 'inappropriate' ratings were reviewed by all members of the research team through a consensus meeting.

Referrals to the HES were assessed by ophthalmologists working in the affiliated hospitals. The diagnoses by HES clinicians were made available to the research team and were cross-referenced with MECS optometrists' diagnoses. HES ophthalmologists also provided feedback on referral appropriateness and referral urgency appropriateness.

\section{Statistical analysis}

SPSS software (IBM, released 2013. IBM SPSS Statistics for Windows, V. 22.0) was used to calculate Cohen's kappa for agreement between the research optometrists assessing clinical safety; $\mathrm{P}<0.05$ was taken to be statistically significant.

\section{RESULTS}

\section{Scheme activity}

In the course of the 12-month monitoring period, a total of 2123 patients were assessed by 10 community optometrists in 13 practices, in 2307 visits. The age range of patients presenting to MECS was from 1 to 93 years (mean age 47 years, $\mathrm{SD}=19$ years, the age data were normally distributed). People of all ethnicities residing in Lambeth and Lewisham had access to the scheme, and patients accessing the scheme had a similar ethnic distribution to that of the two Boroughs. ${ }^{24} 25$

The proportion of patients entering MECS via a GP referral was around two-thirds of the total $(67.3 \%$, $\mathrm{n}=1429)$; self-referral accounted for 568 patients $(26.8 \%)$, pharmacist referrals totalled $2.2 \%$ and a further $3.4 \%$ converted to a MECS appointment from a standard general ophthalmic services sight test. The most common reasons for patients needing a MECS assessment were 'red eye' $(36.7 \%, \mathrm{n}=777)$, 'painful white eye' (11.1\%, $\mathrm{n}=236)$, 'flashes and floaters' $(10.2 \%, \mathrm{n}=216)$ and 'loss of vision' (9.2\%, $\mathrm{n}=194)$. Less frequently reported reasons were 'headaches' (5.3\%, $\mathrm{n}=112)$, 'trauma' $(1.7 \%, \mathrm{n}=36)$ and 'diplopia' $(0.4 \%, \mathrm{n}=8)$. Approximately one MECS

\begin{tabular}{lc}
\hline $\begin{array}{l}\text { Table } 1 \text { Reasons for minor eye conditions scheme (MECS) } \\
\text { visits }\end{array}$ \\
\hline Reason for MECS visit & Patients, $\mathbf{n}(\%)$ \\
\hline Red eye & $777(36.7)$ \\
\hline Painful white eye & $236(11.1)$ \\
\hline Flashes and floaters & $216(10.2)$ \\
\hline Loss of vision & $194(9.2)$ \\
\hline Headaches & $112(5.3)$ \\
\hline Trauma & $36(1.7)$ \\
\hline Diplopia & $8(0.4)$ \\
Other & $538(25.4)$ \\
\hline Swollen lid/lid lump & $122(22.7)$ \\
\hline Watery eyes & $111(20.6)$ \\
\hline $\begin{array}{l}\text { Foreign body sensation, sore/ } \\
\text { dry/gritty eyes }\end{array}$ & $83(15.4)$ \\
\hline Itchy eyes & $56(10.4)$ \\
\hline
\end{tabular}

The reason for the MECS visit was not recorded for six patients.

patient in four $(25.4 \%, \mathrm{n}=538)$ presented with a reason which was not in the predefined categories; more than two-thirds of these $(69.1 \%, \mathrm{n}=372)$ presented with symptoms related to the anterior eye (table 1). A total of 184 patients $(8.7 \%)$ re-presented to their MECS optometric practice for a follow-up examination, predominantly following up minor trauma $(22.2 \%, \mathrm{n}=8$, of patients initially presenting with trauma), diplopia $(12.5 \%, \mathrm{n}=1$, of patients initially presenting with diplopia) and red eye $(11.5 \%, \mathrm{n}=89$, of patients initially presenting with red eye).

Approximately three quarters of MECS patients (75.1\%, $\mathrm{n}=1595)$ remained within community optometric practice; $64.0 \% \quad(\mathrm{n}=1359)$ were diagnosed with pathology managed in the community and in $11.1 \%$ of cases $(n=236)$ the optometrist detected no ocular pathology and the patient was therefore discharged. In total, 5.7\% of the patients $(\mathrm{n}=122)$ were referred to their GP and in $18.9 \%$ of cases $(n=400)$ the examination resulted in referral to the HES (table 2). Of HES referrals $49.1 \%$ were routine, $22.6 \%$ urgent and $28.3 \%$ emergency.

Table 2 Management of patients seen within minor eye conditions scheme (MECS)

\begin{tabular}{lc}
\hline MECS visit outcome & Patients, $\mathbf{n}(\%)$ \\
\hline $\begin{array}{l}\text { Retained in optometric practice } \\
\text { Management of ocular pathology in } \\
\text { practice }\end{array}$ & $1595(75.1)$ \\
\hline $\begin{array}{l}\text { No ocular pathology - discharged } \\
\text { Referral to King's College Hospital }\end{array}$ & $236(11.1)$ \\
$\begin{array}{l}\text { Referral to Guy's and St Thomas's } \\
\text { Hospital }\end{array}$ & $154(7.3)$ \\
$\begin{array}{l}\text { Referral to other hospital eye services } \\
\text { Referral to general practitioner }\end{array}$ & $26(1.2)$ \\
\hline
\end{tabular}


Table 3 Management of the patients after the first minor eye conditions scheme (MECS) visit

Patients managed by the Patients with no ocular community optometrist, $n$ pathology identified, $n$

Reason for MECS visit

\begin{tabular}{|c|c|c|c|c|}
\hline Reason tor MECS VISIt & (\%) & (\%) & (\%) & n (\%) \\
\hline Red eye* & $616(79.3)$ & $10(1.3)$ & $114(14.7)$ & $35(4.5)$ \\
\hline Painful white eye & $152(64.4)$ & 37 (15.7) & 33 (14.0) & $14(5.9)$ \\
\hline Flashes/floaters $†$ & $133(61.6)$ & $23(10.6)$ & $56(25.9)$ & $3(1.4)$ \\
\hline Loss of visiont & $44(22.7)$ & $41(21.1)$ & 99 (51.0) & $9(4.6)$ \\
\hline Headaches & $13(11.6)$ & $58(51.8)$ & $11(9.8)$ & $30(26.8)$ \\
\hline Other† & $375(69.7)$ & $56(10.4)$ & $76(14.1)$ & $30(5.6)$ \\
\hline
\end{tabular}

*Information was not available for two patients in this category.

†Information was not available for one patient in this category.

Presenting complaints most commonly managed in practice were red eyes $(79.3 \%, \mathrm{n}=616)$, painful white eye $(64.4 \%, \mathrm{n}=152)$, flashes/floaters $(61.6 \%, \mathrm{n}=133)$ and trauma $(63.9 \%, \mathrm{n}=23)$ (table 3$)$. Patients presenting with headaches were most commonly discharged without any pathology being identified $(51.8 \%, \mathrm{n}=58)$ or referred to the GP for further investigations $(26.8 \%, \mathrm{n}=30)$. A total of $22.7 \%$ of patients discharged without an identified pathology had an uncorrected refractive error causing the presenting symptoms.

Community optometrists referred patients to their GP for lid neoplasms, dermatitis, migraines, investigation of blood pressure, amaurosis fugax and trigeminal neuralgia. Optometrists also referred patients to their GP for the prescription of oral antibiotics.

The presenting complaint that resulted in the greatest proportion of patients being referred to the HES was diplopia ( $n=8 ; 75 \%$ referred to HES), followed by loss of vision $(n=194 ; 51.0 \%$ referred $)$ and flashes and/or floaters $(\mathrm{n}=216 ; 25.9 \%$ referred). Of the 216 patients presenting with flashes/floaters, $72.2 \%(\mathrm{n}=156)$ were either managed in practice (with diagnoses of posterior vitreous detachment, vitreous floaters/syneresis or ocular migraine) or discharged with no obvious ocular pathology, and approximately a quarter $(25.9 \%, \mathrm{n}=56)$ of patients were referred to the HES. Of the 56 patients referred to the HES due to flashes and floaters, no information of the referral urgency was recorded for two patients. Of the remaining 54 patients, $37.0 \%(\mathrm{n}=20)$ were referred as an emergency (provisional diagnoses: posterior vitreous detachment (PVD), retinal breaks, retinal hole, retinal vascular occlusions or macular haemorrhage), $27.8 \% \quad(n=15)$ urgently (PVD or peripheral retinal haemorrhages) and $35.2 \% \quad(n=19)$ routinely (PVD only); $1.4 \% \quad(\mathrm{n}=3)$ of those presenting with flashes and/or floaters were referred to their GP for investigation of migraine.

The main pathologies managed in optometric practice were related to the eyelid, lacrimal system, orbit, conjunctiva, cornea, sclera and the vitreous (based on the optometrists' provisional diagnoses) (table 4). The provisional diagnoses that most commonly led to a HES referral were disorders of the retina (macular pathologies, retinal vascular pathologies and suspect retinal tears/detachments), corneal ulcers, keratitis, eyelid disorders (chalazia warranting excision, entropion/ectropion and stenosis of the lacrimal passages), glaucoma, uveitis and visual pathway disorders.

Table 4 Management of the patients based on the optometrists' provisional diagnosis, categorised by the International Classification of Diseases codes by WHO

\begin{tabular}{|c|c|c|}
\hline $\begin{array}{l}\text { Optometrists' provisional } \\
\text { diagnosis }\end{array}$ & $\begin{array}{l}\text { Patients } \\
\text { retained in the } \\
\text { community }{ }^{\star}, n \\
(\%)\end{array}$ & $\begin{array}{l}\text { Patients } \\
\text { referred to } \\
\text { HES, n (\%) }\end{array}$ \\
\hline Eyelid, lacrimal system, orbit & $335(81.3)$ & $60(14.6)$ \\
\hline Diseases of the conjunctiva & $357(87.5)$ & $19(4.7)$ \\
\hline $\begin{array}{l}\text { Disorders of the cornea and } \\
\text { sclera }\end{array}$ & $443(82.6)$ & $74(13.8)$ \\
\hline $\begin{array}{l}\text { Disorders of the iris and ciliary } \\
\text { body }\end{array}$ & $1(3.4)$ & $27(93.1)$ \\
\hline Disorders of the lens & $23(60.0)$ & $18(40.0)$ \\
\hline Disorders of choroid and retina & $6(6.3)$ & $87(90.6)$ \\
\hline Glaucoma & $4(10.5)$ & $33(86.8)$ \\
\hline $\begin{array}{l}\text { Disorders of vitreous body and } \\
\text { globe }\end{array}$ & $117(82.4)$ & $25(17.6)$ \\
\hline $\begin{array}{l}\text { Disorders of optic nerve and } \\
\text { visual pathway }\end{array}$ & $0(0.0)$ & $6(100.0)$ \\
\hline $\begin{array}{l}\text { Disorders of ocular muscles, } \\
\text { binocular movement, } \\
\text { accommodation and refraction }\end{array}$ & $55(87.3)$ & $7(11.1)$ \\
\hline Visual disturbances & $35(60.3)$ & $14(24.1)$ \\
\hline
\end{tabular}

Patients referred to the general practitioner are not shown in this table. For a total of 285 patients, no WHO disease code was applicable to the diagnosis.

* Patients managed in optometric practice or discharged without a pathology. 
Table 5 Details of the patients' management rated as inappropriate by the research team

\begin{tabular}{ll}
\hline Optometrists' diagnosis & Reason for inappropriate rating \\
\hline Corneal abrasion & Inappropriate patching* $\dagger$ \\
\hline Seasonal allergic conjunctivitis & Unnecessary referral to GP \\
\hline Recurrent painful white eye & Unnecessary referral to HES \\
\hline Viral conjunctivitis & Unnecessary referral to HES \\
\hline Bacterial conjunctivitis & Unnecessary referral to GP \\
\hline Possible CL-related infection & Inappropriate treatment with chloramphenicol \\
\hline Uncertain & Prescription error (mast-cell stabiliser and antihistamine) \\
\hline Allergic reaction and stye & Inappropriate treatment with chloramphenicol and sodium cromoglycate \\
\hline Recurring allergic conjunctivitis & No attempt to try antihistamines or mast-cell stabilisers prior to referring to GP, no \\
\hline Macular RPE changes & IOP measurement prior to suggesting steroid drops to be prescribed by the GP* ${ }^{*}$ \\
\hline Glaucoma suspect & Inappropriate urgency for HES referral \\
\hline Single floater & Inappropriate urgency for HES referral \\
\hline
\end{tabular}

*The patient could have come to harm due to the optometrists' management.

†The patient returned to the practice, and it was confirmed that the abrasion had healed without any complications.

$\ddagger$ The final outcome of these cases could not be established.

$\mathrm{CL}$, contact lens; GP, general practitioner; HES, hospital eye services; IOP, intraocular pressure; RPE, retinal pigment epithelium.

\section{Prescription of medication}

Medication was supplied to $48.3 \% \quad(\mathrm{n}=1025)$ of MECS patients. Ocular lubricants were most commonly supplied (29.7\% of all patients seen through MECS, $\mathrm{n}=630)$, followed by topical antibiotic drops (ie, chloramphenicol or fusidic acid, $12.1 \%, \mathrm{n}=257$ ), topical and systemic antiallergy agents $(6.1 \%, \mathrm{n}=129)$ and systemic analgesia $(0.5 \%, \mathrm{n}=10)$.

\section{Clinical safety}

Overall agreement between the graders assessed on a sample of 44 records was 'almost perfect' according to the Landis-Koch criteria (average kappa $=0.92$, range $0.87-0.97)$. Of the 220 records subsequently reviewed, $5.5 \%(\mathrm{n}=12)$ were rated as inappropriate. Details of those cases where the assessment/management was rated as inappropriate are listed in table 5 ; in the opinion of the graders, three of the patients whose management was rated as inappropriate could have come to harm by the optometrists' management $(1.36 \%$ of all patient records reviewed).

Collaborating ophthalmologists from Kings College Hospital and Guy's and St Thomas' Hospital reviewed $72.0 \%$ of the HES referrals (either community optometrists' referral letters and clinical notes or HES clinical records). Of these, $89.2 \%$ were judged to have been appropriately referred and $78.2 \%$ were referred with appropriate urgency. For $59.7 \%$ of the HES referrals, feedback was provided after an ophthalmologist reviewed the HES records and included diagnosis by a HES ophthalmologist, management and a judgement on the appropriateness of referral and referral urgency. Of these $87.9 \%$ had been appropriately referred according to an ophthalmologist. Inappropriate referrals (ie, unnecessary referrals to the HES) were related to long-standing corneal scars, anisocoria, PVD, refractive error, blepharitis, chalazia, conjunctivitis, macular degeneration, long-standing toxoplasmosis scars, refractive error and functional vision loss (online supplementary appendix 1). Of the appropriate HES referrals, $70 \%$ were made with appropriate urgency; $28.3 \%$ of referrals were referred more urgently than necessary; $1.7 \%(n=4)$ of all referrals were made with a lower urgency than appropriate; these referrals were related to a corneal foreign body, scleritis and PVD (online supplementary appendix 2).

\section{DISCUSSION}

The Lambeth and Lewisham MECS was designed to reduce ophthalmology referrals in the two London boroughs, after an earlier audit by Lambeth Clinical Commissioning Group (CCG) indicated that approximately $38 \%$ of acute ophthalmology referrals could have been managed in a community setting, for example, by a community optometrist or by the GP. ${ }^{26}$ This finding is consistent with an audit of cases seen in a dedicated ophthalmic A\&E department in central London. ${ }^{7}$ The pilot Lambeth and Lewisham MECS was supported by a robust clinical governance framework, where structured training was required for optometrists' participation. Participating community optometrists had access to specially designed training (Local Optical Committee Support Unit and WOPEC), evidence-based clinical management guidelines freely provided by the College of Optometrists, ${ }^{22}$ attended A\&E sessions at their local HES and maintained scheduled contact with participating consultant ophthalmologists, who also provided feedback on HES referrals. Participating community optometrists were permitted to exercise clinical judgement, as 
it has been shown that participation in ESS provides an exposure to more challenging clinical cases, allowing optometrists to use clinical skills to a greater extent. Local CCGs, collaborating hospitals and the Eye Group (comprising commissioners, GPs, ophthalmologists and optometrists) met on a regular basis to discuss the activity and overall usefulness of the scheme.

A total of 2123 patients drawn from a wide range of ethnic groups used the scheme within the first year; and $67.3 \%$ of these patients were referred from their GP. Previous research supports the finding that GPs favour assessment of patients presenting with ophthalmic complaints by optometrists (especially in cases that would be hard to diagnose by GPs, eg, red eyes, flashes and floaters $)^{1627}$ and highlights the value of specialist tools (slit-lamp biomicroscopy, fundoscopy) in the diagnosis and management of commonly presenting ocular pathologies. More than $80 \%$ of the patients that were diagnosed with anterior eye conditions, binocular vision disturbances, vitreous pathologies and ocular migraines were retained in the community and appropriately managed by the optometrists; a large proportion $(60 \%)$ of patients diagnosed with cataracts were also retained in the community.

The above pathologies have independently been shown to be satisfactorily managed by community services. ${ }^{7}$ The optometrists' specialist knowledge of eye pathology, as well as the use of dedicated ESS appointments, has allowed optometrists to tailor their clinical assessment to patients' needs and thoroughly discuss management options. The findings of this study indicate that optometrists are in a good position to differentiate between various ocular pathologies and to assess risk; the vast majority of choroid, visual pathway and optic nerve pathologies were referred to the HES, indicating that the participating community optometrists understand the limitations of an ESS and a MECS specifically.

The appropriateness of HES referrals via MECS was better in this study compared with previously published data. $^{28}$ A total of $95 \%$ of the patients seen within the scheme were assessed as being appropriately managed, with no clinical safety concerns. The management of patients in this ESS was shown to be safe, through a method involving research team consensus and ophthalmology evaluation of referrals. According to the HES consultant ophthalmologists, approximately $11 \%$ of referrals were judged unnecessary by ophthalmologists who monitored the scheme. Referrals were generally sent with an appropriate degree of urgency. Of those judged to be inappropriate, $>90 \%$ were sent with greater urgency than considered necessary. These findings indicate a clinically safe service, despite some differences of opinion between optometrists and ophthalmologists regarding referral urgency. These differences may be related, not only to training and clinical experience, but arguably also to knowledge of the evolving treatment options for certain pathologies.
A number of ESSs have been developed over the last decade; the PEARS scheme in Wales is similar to this MECS. Comparison with previous schemes will allow improvement of the services provided to patients and estimates of the cost savings to the NHS. A total of $75.1 \%$ of patients were retained in community optometric practices (either managed by community optometrists or discharged) when compared with $66 \%$ of patients who accessed the Wales PEARS ${ }^{28}$ or other smaller schemes. ${ }^{29} 30$ A total of $8.7 \%$ of patients returned to community optometric practice for a follow-up appointment; this figure is lower than the average follow-up rate in similar ESS schemes which has been reported to be $22.13 \%,{ }^{31}$ although some schemes have reported follow-up rates comparable to the Lambeth and Lewisham MECS. ${ }^{29} 3032$ The vast majority of patients followed up by community optometrists had symptoms relating to the anterior eye, minor trauma or uncorrected refractive errors. Referral rates to GPs in the Lambeth and Lewisham MECS (5.7\%) were also below the reported UK average for similar schemes $(8.63 \%)^{31}$ and lower than in the PEARS scheme $(16 \%) \cdot{ }^{28}$ HES referral rates for other MECS schemes in the UK have been reported to average $19.3 \% .^{31}$ Approximately $18.9 \%$ of patients accessing the Lambeth and Lewisham MECS were referred to the HES, a rate similar to the PEARS scheme (18.2\%).

The MECS community optometrists supplied therapeutic agents to $48.3 \%$ in first and follow-up visits, despite a lack of non-medical prescribing qualification. Medication was supplied using a 'signed order' that could be presented to the pharmacist. A system was established for patients exempt from NHS prescription charges to allow pharmacies to provide medication free of charge. Ocular lubricants were the most commonly supplied ocular medication, followed by topical antibiotic eye drops. These interventions represent medications that can freely be prescribed by optometrists under the Entry Level Medicines Act exemptions. ${ }^{20}$

Ophthalmologists' collaboration has been a key factor in the development of this pilot ESS, providing mentoring to community optometrists and feedback on referral safety. The scheme also benefited from a high level of GP engagement, with approximately two-thirds of patients being referred into MECS by local GPs. This study did not follow the principles of randomised controlled trials since an observational pragmatic evaluation is more suitable for community healthcare services research. ${ }^{33}$ The Lambeth and Lewisham MECS is one of the first ESS to be comprehensively evaluated; results suggest that the scheme is safe for patients, while providing a service that also benefits the NHS. ${ }^{18}$ Collaboration between eye care providers has promoted the scheme's popularity and increased its chances of sustainability. Appropriate training, support by local CCGs and ongoing collaboration between eye care providers are necessary to design and operate safe and successful ESSs that reduce hospital attendances. 
Contributors EK was involved in the design of the study, in the acquisition and analysis of the data and wrote the manuscript. DFE was involved in the design of the study, data analysis, drafting and critical revision of the manuscript. RAH was involved in the design of the study, data analysis, drafting and critical revision of the manuscript. GL and SJ were involved in the design of the study, analysis of the data and critical revision of the manuscript. JGL was involved in the design of the study, data analysis, drafting and critical revision of the manuscript. All authors read and approved the final manuscript.

Funding This work was funded by the College of Optometrists as part of the Enhanced Scheme Evaluation Project.

Competing interests None declared.

Patient consent Obtained.

Ethics approval The study was approved by the Research and Ethics committee of the School of Health Sciences, City, University of London, and followed the principles of the Declaration of Helsinki.

Provenance and peer review Not commissioned; externally peer reviewed.

Data sharing statement Additional unpublished data may be available by contacting the authors.

Open Access This is an Open Access article distributed in accordance with the Creative Commons Attribution Non Commercial (CC BY-NC 4.0) license, which permits others to distribute, remix, adapt, build upon this work non-commercially, and license their derivative works on different terms, provided the original work is properly cited and the use is non-commercial. See: http://creativecommons.org/ licenses/by-nc/4.0/

(C) Article author(s) (or their employer(s) unless otherwise stated in the text of the article) 2018. All rights reserved. No commercial use is permitted unless otherwise expressly granted.

\section{REFERENCES}

1. NHS Digital. Hospital episode statistics. hscic.gov.uk/hes (accessed 13 Feb 2017).

2. NHS Scotland. Information Services Division. http://www. isdscotland.org/ (accessed 13 Feb 2017).

3. NHS Wales. Sources of Data, 2017. http://www.wales.nhs.uk/ statisticsanddata/sourcesofdata (accessed 13 Feb 2017).

4. Smith HB, Daniel CS, Verma S. Eye casualty services in London. Eye 2013;27:320-8.

5. RNIB. Saving money, losing sight. 2013.

6. Foot B, MacEwen C. Surveillance of sight loss due to delay in ophthalmic treatment or review: frequency, cause and outcome. Eye 2017;31:771-5.

7. Hau S, loannidis A, Masaoutis P, et al. Patterns of ophthalmological complaints presenting to a dedicated ophthalmic Accident \& Emergency department: inappropriate use and patients' perspective. Emerg Med J 2008;25:740-4.

8. Jones NP, Hayward JM, Khaw PT, et al. Function of an ophthalmic "accident and emergency" department: results of a six month survey. Br Med J 1986;292:188-90.

9. Kheterpal S, Perry ME, McDonnell PJ. General practice referral letters to a regional ophthalmic accident and emergency department. Eye 1995;9:67-9.

10. Fenton S, Jackson E, Fenton M. An audit of the ophthalmic division of the accident and emergency department of the Royal Victoria Eye and Ear Hospital, Dublin. Ir Med J 2001;94:265-6.
11. Bhopal RS, Parkin DW, Gillie RF, et al. Pattern of ophthalmological accidents and emergencies presenting to hospitals. J Epidemiol Community Health 1993;47:382-7.

12. Winkler F, Meads G. Primary Eye Care Development in Camden and Islington: Department of Health. 1998.

13. Davey CJ, Green C, Elliott DB. Assessment of referrals to the hospital eye service by optometrists and GPs in Bradford and Airedale. Ophthalmic Physiol Opt 2011;31:23-8.

14. Pierscionek TJ, Moore JE, Pierscionek BK. Referrals to ophthalmology: optometric and general practice comparison. Ophthalmic Physiol Opt 2009;29:32-40.

15. Association of Optometrists. Primary Care Development Information pack. 1999

16. Konstantakopoulou E, Harper RA, Edgar DF, et al. A qualitative study of stakeholder views regarding participation in locally commissioned enhanced optometric services. BMJ Open 2014;4:e004781.

17. Baker H, Harper RA, Edgar DF, et al. Multi-stakeholder perspectives of locally commissioned enhanced optometric services. BMJ Open 2016;6:e011934

18. Mason $\mathrm{T}$, Jones $\mathrm{C}$, Sutton $\mathrm{M}$, et al. Retrospective economic analysis of the transfer of services from hospitals to the community: an application to an enhanced eye care service. BMJ Open 2017;7:e014089.

19. Konstantakopoulou E, Edgar DF, Harper RA, et al. Evaluation of a minor eye conditions scheme delivered by community optometrists. BMJ Open 2016;6:e011832.

20. Saw SM, Foster PJ, Gazzard G, et al. Undercorrected refractive error in Singaporean Chinese adults: the Tanjong Pagar survey. Ophthalmology 2004;111:2168-74.

21. World Health Organisation. International Statistical Classification of Diseases and Related Health Problems 10th Revision (ICD-10), 2015. http://apps.who.int/classifications/icd10/browse/2015/en\#/VII (accessed 7 Sep 2015).

22. College of Optometrists. Clinical management guidelines. 2015 http://www.college-optometrists.org/en/professional-standards/ clinical_management_guidelines/

23. LOC Suppport Unit. Primary Eyecare Assessment \& Referral Service (PEARS). 2008.

24. UK Census data. Lambeth, 2011. http://www.ukcensusdata.com/ lambeth-e09000022\#sthash.E3Thpt1n.dpbs (accessed 2 Jun 2015).

25. UK Census data. Lewisham, 2011. http://www.ukcensusdata.com/ lewisham-e09000023\#sthash.e0LRJVTU.dpbs (accessed 2 Jun 2015).

26. Lambeth Clinical Commissioning Collaborative/Lambeth Business Support Unit. Improving Health in Lambeth, 2012. https://lpbcc.files. wordpress.com/2012/05/3-0-14052012-improvinghealth-in-lambethed-3.pdf (accessed 16 March 2017).

27. Ewbank A. The optometrist and primary eye care. $\mathrm{Br} J$ Ophthalmol 1997;81:100-1

28. Sheen NJ, Fone D, Phillips CJ, et al. Novel optometrist-led all Wales primary eye-care services: evaluation of a prospective case series. Br J Ophthalmol 2009;93:435-8.

29. McCracken M. Auditing an acute eye pathway. Optometry Today 2013;22:34-7.

30. Greenwood L. Auditing of a referral refinement service in Hull. Optometry Today 2013;25:24-6.

31. Cottier K. An audit of the Primary Eye-care Acute Referral Scheme (PEARS) within NHS Bromley Clinical Commissioning Group (CCG) Optometry in Practice 2015;16:21-32.

32. Craven W. Monitoring activity in a minor eye conditions service. Optometry Today 2015;4:39-41.

33. Mossialos E, Naci H, Courtin E. Expanding the role of community pharmacists: policymaking in the absence of policy-relevant evidence? Health Policy 2013;111:135-48. 